\title{
CONFLICTO GENIC POTENTIAL OF MIGRANT AND REFUGEE IMAGE IN THE INTERNET WITHIN THE CONTEXT OF INTERNATIONAL INFORMATION SECURITY PROVISION
}

\author{
Roman V. Penkovtsev ${ }^{1}$ \\ Natalia A. Shibanova ${ }^{2}$ \\ Ghamdan Hammod Moqbel Khalid ${ }^{3}$
}

\begin{abstract}
The article is devoted to the analysis of report visual component on modern migration processes circulating in the communication space of the Internet in the context of international information security provision. The provision of international, regional and national security at the request of the President V.V. Putin is the main priority of Russian Federation state policy at the present stage. International information security acts as an integral part of international relations and is directly related to the settlement of world politics issues. The instability of modern migration processes poses a serious threat to the national interests of Russia, which is reflected visually in the electronic media. Based on the results
\end{abstract} obtained during the implementation of two applied studies, the main substantive components are highlighted - the plots of visual messages and their influence on the nature of a communication subject perception by the audience, i.e. by migrants. The plots that contribute to the communication conflict potential increase and decrease were identified empirically. They can have practical applications in the process of a constructive dialogue development and the interaction in a complex modern world.

Keywords: international relations, international conflicts, international information security, migration processes, the image of migrants,

\footnotetext{
${ }^{1}$ Kazan Federal University, Institute of International Relations, History and Oriental Studies, email: Roman.Penkovtsev@kpfu.ru, tel.: +78432928489.

${ }^{2}$ Kazan Federal University, Institute of International Relations, History and Oriental Studies

${ }^{3}$ Kazan Federal University, Institute of International Relations, History and Oriental Studies
} 
Internet visualization, electronic mass media.

\section{Introduction}

In the modern world, information is an important resource, and the communication process undergoes significant changes, becoming more and more medialized, virtualized and visualized. Nowadays, along with the development of the information sphere, we can observe the growth of different conflict amount, the significant role of which belongs to the media. One of international and regional conflict consequences was the intensification of migration processes, which could not be left without media attention. The way in which the media covers this problem depends not only on the perception of migrants and their attitude towards them, but also on migration policy, due to the fact that the media audience is represented by voters. The perception and the attitude to migrants, foreign and domestic policies, social tension and conflicts have a significant impact on the visual images produced by the media.

Materials and methods
268

Many researchers, including $\mathrm{P}$. Shtompka, note the feature of the modern world - the combination of visual image intense flow with the system process of virtual reality creation [1]. According to J. Baudrillard, we live in the postmodern epoch, when imitation dominates in the world of "hyperreality", when an image and signs displace real impressions and experience [2]. Under these conditions, images that transfer information, emotions and values acquire great importance for communication, they construct and shape our comprehension of the world.

In the society where the access to information and to the audience becomes almost limitless, the media make a significant impact on the society by an information picture of the world and media image creation that affect the collective and individual consciousness. The communication between the media and the audience often occurs through combined texts that combine visual and verbal components. The most important role in such texts is played by photography, which records social facts and phenomena, and also interprets them. 
P. Bourdieu considers

photography as the way of group identity reproduction, the method of social stratification labeling that possesses a compulsory force, as the mechanism of communication development [3]. Photographs along with a headline and an annotation to materials are designed to attract the Internet reader, make him stop in a modern dynamic world, to "click" and to get acquainted with the full version of the material. If a reader does not read an article, it is the photo that largely determines his attitude to its subject matter. Accordingly, the sociological knowledge of mass media message visual component is relevant. Taking into account the relationship of visual images with the phenomena of collective identity and social stratification, inevitably associated with the division into friends and foreigners, there is a demand for a conflict analysis - the identification of a conflict potential presence and strength concerning various images reproduced in photographs.

Many of the online publications devoted to migration are accompanied by photographs. This article contains the results of two studies of such images.
The first one was represented by the analysis of about 400 photos during December 2015 - January 2016. The time frame is explained by the hypothesis of composition change and the richness of migrant image under the influence of New Year's Eve events in Cologne. The choice of Internet resources is explained by the amount of the Internet audience (the share of active audience in Russia makes 62 million people) [4], its active life position (the age of $50 \%$ of the audience at the age of 21-34 years, $46.9 \%$ have higher education and $25.8 \%$ have incomplete higher education) [5], a high level of confidence in the Internet [6]. The analyzed materials were located on the pages of the three most cited Internet resources: Rbc.ru, Lenta.ru, Gazeta.ru [7]. The materials of Deutsche Welle website in Russian, offering news, analysis, comments and reports from Germany and Europe to the Russian audience have broadened the research field qualitatively.

The second study was aimed at the identification of individual perception specifics and an image interpretation. The study was the survey of a group of students at the age of 19-20 
of both sex, who were shown the most typical photographs of "migrant issues". The respondents were asked to answer a number of questions aimed at the photograph content component revealing, the emotional relationship to the heroes of the photos, the social distance with them on the basis of the Bogardus scale (where 1 is the minimum distance tied to the judgment of "photo hero acceptance as close relatives through marriage"; 2 - "as close friends", 3 - "as neighbors", 4 - "as colleagues at work", 5 as "fellow citizens", 6 - "only as the tourists in one's own country", 7 maximum distance - "would prefer not see in my country"). The evaluations of personal, group and public conflict likelihood with the photo heroes using a 10 -point scale $(0$ - the absence of a conflict potential, 10 - maximum likelihood).

\section{Results and Discussion}

As the part of the first study, a coding protocol was compiled, consisting of 27 content criteria - typical plots. The vast majority of photographs are documentary ones, causing more confidence. Additional confidence shall appear from the opinions of experts and politicians, whose photographs are placed in $20 \%$ of publications concerning the migration topic. Gazeta.ru, Lenta.ru, Rbk.ru has 16\% of such pictures from the total number, and $24 \%$ in DW, which can be explained by the greater propensity of DW to expert assessments, authoritative opinions and political correctness.

The next criterion is "the photos of migrants without migrants" - the images do not contain the images of migrants or these images are extremely small, made from the back, etc. Such pictures make $39 \%$ from the total number of photos. They have approximately the same number in all editions, but there are $30 \%$ of such images in December, and $41 \%$ of the total number in January. More often such photographs depict the representatives of the police or the armed forces. DW pages have the photos of "enforcers" which make $21 \%$, in other publications these photos make 31\%; In December 2015 there were $30 \%$ of such pictures, and already $41 \%$ of the total number in January. It is impossible to interpret this trend unambiguously. On the one hand, police and military force images is a 
symbol of law and order, the message of the audience that everything is "under control". On the other hand, the police are often associated with crime, and the military forces are associated with armed conflicts, in other words, if there is police and army, not everything is in order then.

Six photographs in the second study included "enforcers". The photograph of the policemen in Cologne without migrants [9] (photo number 4 photo numbering corresponds to the order in which they were presented to respondents during the research) aroused a sense of interest among the absolute number of respondents (89\%), the social distance was 4.6 units, the probability of a personal conflict was rated by the respondents as one unit, with their group - 1.3, with their country - 2.9. The photo of the violator arrest by police (photo No. 7) [10] caused negative feelings of contempt (22\%) and disgust (17\%), except for a sense of interest (56\%), the social distance was 5.9 units, and the respondents estimated the likelihood of a conflict in $1.3 ; 2.6$ and 4.5 respectively. Photo No. 1 accompanied the material issued on January 26, 2016 about "Swedish police which escaped from the crowd of migrants" [11], but the photo itself made on November 4, 2015, illustrates the materials about the evacuation of the migrant camp by Swedish policemen [12]. Thus, the image of the event main characters is being replaced - the Gypsies had nothing to do with the incident of January 26. The reasons for the substitution, most likely, lie in the desire of the media to attract the attention of the audience, accompanying the news with a bright visual series. The consequences of such a substitution can be the most undesirable - the blaming of the innocent in this incident, the inciting of intolerance and conflict interaction with the representatives of Gypsies. This photo often caused negative feelings of suffering / grief (83\%), disgust (50\%), fear (33\%) and contempt (28\%) among students. The social distance made 6.5 units, and the respondents estimated the probability of the conflict at $2.9 ; 3.5 ; 6.8$ respectively.

The next three photos are among the main images of 2015 according to Reuters. Photo No. 5 demonstrates a mounted policeman leading a group of Syrian refugees [13]. The picture caused the feelings of 
interest $(67 \%)$, surprise $(33 \%)$, fear $(33 \%)$ and suffering $(28 \%)$. The social distance was 5.8 units, the probability of a conflict made $1.3 ; 2.8 ; 5.3$. Photo No. 6 recorded a police cordon, crowding refugees after a fight at the GrecoMacedonian border [14]. This picture caused negative feelings more sharply: suffering (83\%), fear $(72 \%)$, contempt $(51 \%)$ and anger (33\%). The social distance made 5 units, the probability of a conflict was estimated by students at $0.8 ; 2.2 ; 4.6$. Photo No. 9 is a portrait of a refugee who did not manage to get to Hungary, after a complete border closure between Hungary and Serbia [15]. This picture caused mostly negative feelings: fear $(61 \%)$, disgust (39\%), anger (33\%) and interest (33\%). According to social distance parameters and the likelihood of a conflict, this photo is close to the indicators of the photo No. 1: social distance made 6.5; The probability of the conflict made $2.0 ; 3.4 ; 6.2$. The "portrait" photos of "typical" migrants, i.e. the young men are represented on photo № 9 and on photo № 3, where a young Iranian demonstrates his wired mouth the sign of protest against the actions of the Macedonian authorities, allowing only the migrants from Syria [16]. Photo
272

No. 3, like photo No. 9, causes mostly negative feelings: suffering (67\%), fear (50\%), interest (44\%). According to the parameters of social distance and the likelihood of conflict, these photos are close: the social distance from photo № 3 makes 6,1 ; the probability of a conflict makes $1.4 ; 3.0 ; 5.7$.

The pictures of politicians, experts and the pictures "without migrants" make up more than $50 \%$ of the total number of photographs. Thus, the media try to avoid an open visual message. The frequent plot is a plot of "movement" - the pictures capture the territorial movement of migrants in various ways (19\% of the total number of images). $6 \%$ of images are the images of various boats and water, through which migrants move.

In general, the portrait of a migrant is the following one. They come from the East or Africa, moving in large groups $(11 \%$ of cases recorded 25 or more migrants simultaneously), often with families. $18 \%$ of the pictures show the children of migrants (in January the number of such pictures decreased by $10 \%$ and made $16 \%$, DW publishes such pictures more often than Gazeta.ru, Lenta.ru and Rbk.ru - 22\% and 13\% 
ISSN | 2179-7137 | http://periodicos.ufpb.br/ojs2/index.php/ged/index

respectively). 4 photos of children were presented for respondents. The results from photo No. 6 suggest that it is the child's presence that reduces the social distance and the likelihood of a conflict. The photo № 2 demonstrates a Syrian refugee who rescues a child in the water near the island of Lesbos [17]. The level of social distance is 4.3 , the probability of a conflict is $0.1 ; 1.0 ; 3.5$. The photo № 8 demonstrates a Syrian family with children overcoming the barbed wire in the attempt to get to the territory of Hungary [18]. The social distance with the heroes of the picture was determined by respondents at 3.8, and the probability of a conflict at $0.3 ; 0.9 ; 3.6$. A wellknown photo No. 10 captured the moment when a refugee fell with a child in his arms from a footboard of a Hungarian cameraman [19]. The social distance made 4.6 units, the probability of a conflict is $0.9 ; 2.3 ; 3.0$. Thus, the image of children is a powerful factor for social distance reduction, the reduction of any type of conflict likelihood. Let's note that all the pictures are the images of children in a difficult life situation, overcoming difficulties with their parents. Women were recorded by $18 \%$ of pictures (in December the amount of such photos was $21 \%$, in January - 17\%, DW - 21\%, Gazeta.ru, Lenta.ru, Rbk.ru $14 \%$ ) and, as a rule, in traditional clothes (10\% of the total number of images) which is associated with the religious affiliation of migrants. An absolute majority of adult migrants are the people of working age, the representatives of the older generation met only in 5 pictures.

$10 \%$ of the pictures demonstrate fence, grilles, wire, designed to limit the flow of migrants (in December these pictures made $18 \%$ of the total amount, and in January - 8\%). In addition to the designated plots, there are less common images: "Centers, migrant camps" - 11\% (DW publishes such photos 4 times more frequently - 16\%); "Meetings against migrants" - 5\%. Then there are the stories that recorded by 5 photographs (maximum): "migrants' protests", "posters", usually compassionate ones in the hands of migrants, "assistance" (medical one, distribution of food, etc.), "the rallies in support of migrants", "aggression, clashes of migrants", "fires and their consequences", "the detention of migrants", "the training of migrants", "the drawings of migrant children", "deportation", "luck of migrants", "migrants' documents, "management 
communication with migrants", "maskpixilization of a face". $12 \%$ of the total number of photos represent the share of 14 enumerated plots.

\section{Conclusions}

According to photographs in electronic mass media, migrants are young, active, often family people from the East or the African continent. They are numerous and are in motion. In order to control them, the police, the army and various defense structures are used. A few photographs that record the process of adaptation and integration of migrants, their heavy share and the provision of assistance to them do not have a significant impact on the overall impression of danger and threat. Respondents demonstrate a significant social distance with migrants. The image of migrant children in a difficult life situation is the factor of social distance and any conflict likelihood reduction. A high "conflict potential" is carried by "portrait" photos of "typical migrants". The pictures with police officers without the record of refugees cause positive feelings. If a photo identifies refugees along with policemen, then positive
274

feelings are reduced, and negative ones are increased. All the photos have a certain conflict-related charge, as evidenced by the tendency of a conflict probability increase when you move from the level of interpersonal conflicts to the level of conflict with a state, while respondents are not the direct representatives of the host community. DW uses visual messages with low conflict potential significantly more often (depicting children, their drawings, the successful experience of migrant integration and adaptation) and with a neutral charge (the image of experts and politicians).

A certain tendency of the media can minimize the visualization of a communication subject by several objectives: the adherence to the rules of political correctness and journalistic ethics, the desire to avoid the publication of provocative photographs and not to increase the level of social tension. However, an incomplete, partial, incorrect informing of the audience about the crisis subject does not contribute to this crisis resolution, but it can become a source of social phobias, prejudices spread and development and, 
as a result, the conflict interactions with migrants.

The events in Cologne influenced ambiguously the image of a migrant: an increase of photograph amount without migrants and with "enforcers", the reduction of pictures showing obstacles, women and children. Together, these trends do not change the level of visual message conflict potential.

\section{Summary}

Creating a migrant's image, electronic media take it beyond the normative framework, position him as a foreigner, who is different from ordinary people by many markers, which does not contribute to the normalization of the relationship between residents and migrants. The "alienation" of migrants can transfer migrants into the category of an extreme case - a Stranger - an Enemy. A migrant as an Enemy or as a Foreigner creates a sense of danger, tension and anxiety. It is known that the process of an Enemy development contributes to the consolidation and the mobilization of society, but it does not facilitate the establishment of relations between migrants and the host community,
275

creating the prerequisites for destructive conflicts. Modern mass media not only cover migration processes, but accompany them, directly influencing the events and their consequences. Carrying out the communication with society about migration problems, the media is greatly responsible for the development of constructive social relationships in difficult conditions. If the present vector of a conflict demonstration is preserved, the problems may be predicted to a further increase of threat and social tension, and ultimately to the increase of destructive conflict amount.

\section{Acknowledgements}

The work is performed according to the Russian Government Program of Competitive Growth of Kazan Federal University.

\section{References}

Shtompka P. (2007). Visual sociology. Photography as the method of research. M.: Logos, pp. 5-7.

Baudrillard Jean. (1988). The Evil Demon of Images. Sydney: Sydney University Press. 
Bourdieu P. (2014). Public art. Experience about the social use of photography. Praxis. 464 p.

Internet in Russia: the dynamics of penetration. Summer of 2015 // Public Opinion Foundation (FOM). - 2015. - 30 October. http://fom.ru/SMI-iinternet/12369 (date of appeal: 12.02.2017).

The portrait of the Russian Internet user // Business Center of the Republic of Tatarstan - the Internet portal TatCenter.ru. - 2005. - The 22nd of June. http://info.tatcenter.ru/article/28270/ (date of appeal: 14.02.2017).

Russians are less likely to trust television // Synovate Comcon company - 2011. http://www.comcon-

2.ru/default.asp?artID=2749 (date of appeal: 14.02.2017).

Information-analytical system "Medialogiya". - 2015. - November. http://www.mlg.ru/ratings/federal_medi a (date of appeal: 14.02.2017).

The photo haz.de by Gazeta.ru http://www.gazeta.ru/comments/2016/0
276 1/11_e_8015243.shtml (date of appeal: 14.02.2017).

The photo: imago stock\&people / Globallookpress.com by Lenta.ru https://lenta.ru/news/2016/02/24/cologn e_update/ (date of appeal: 14.02.2017).

The photo: Drago Prvulovic / TT News Agency / Reuters на Lenta.ru http://lenta.ru/news/2016/01/26/sweden (date of appeal: 14.02.2017).

For example: http://www.japantimes.co.jp/news/2015 /11/04/world/social-issuesworld/swedish-cops-clear-gypsy-campdeemed-squalid-denizens-offeredflights-romania/\#.VvHD9nqnEak (date of appeal: 14.02.2017).

The photo: Srdjan Zivulovic / Reuters by Lenta.ru https://lenta.ru/photo/2015/12/14/reuters poy/\#1 (date of appeal: 14.02.2017)

The photo: Alexandros Avramidis / Reuters by Lenta.ru https://lenta.ru/photo/2015/12/14/reuters poy/\#16 (date of appeal: 14.02.2017) 
Periódico do Núcleo de Estudos e Pesquisas sobre Gênero e Direito Centro de Ciências Jurídicas - Universidade Federal da Paraíba V. 8 - No 05 - Ano 2019 ISSN | 2179-7137 | http://periodicos.ufpb.br/ojs2/index.php/ged/index

The photo: Stoyan Nenov / Reuters by

Lenta.ru

https://lenta.ru/photo/2015/12/14/reuters

poy/\#30 (date of appeal: 14.02.2017)

The photo: Yannis Behrakis / Reuters by

Lenta.ru

https://lenta.ru/photo/2015/12/14/reuters

poy/\#19 (date of appeal: 14.02.2017)

The photo: Alkis Konstantinidis /

Reuters by Lenta.ru

https://lenta.ru/photo/2015/12/30/pictur

estories/\#5 (date of appeal: 14.02.2017)

The photo: Bernardett Szabo / Reuters by

Lenta.ru

https://lenta.ru/photo/2015/12/30/pictur

estories/\#10 (date of appeal: 14.02.2017)

The photo: Marko Djurica / Reuters by

Lenta.ru

https://lenta.ru/photo/2015/12/30/pictur

estories/\#13 (date of appeal: 14.02.2017 